\title{
Person-Centered Emotional Support and Gender Attributions in Computer-Mediated Communication
}

\author{
Erin L. Spottswood ${ }^{1}$, Joseph B. Walther², Amanda J. Holmstrom³ ${ }^{2}$, \& Nicole \\ B. Ellison 4 \\ 1 Department of Communication, Cornell University, Ithaca, NY 14850, USA \\ 2 Department of Communication and Department of Telecommunication, Information Studies \& Media, \\ Michigan State University, East Lansing, Ml 48824, USA \\ 3 Department of Communication, Michigan State University, East Lansing, MI 48824, USA \\ 4 School of Information, University of Michigan, Ann Arbor, MI 48109, USA
}

\begin{abstract}
Without physical appearance, identification in computer-mediated communication is relatively ambiguous and may depend on verbal cues such as usernames, content, and/or style. This is important when gender-linked differences exist in the effects of messages, as in emotional support. This study examined gender attribution for online support providers with male, female, or ambiguous usernames, who provided highly person-centered (HPC) or low person-centered (LPC) messages. Participants attributed gender to helpers with genderambiguous names based on HPC versus LPC messages. Female participants preferred HPC helpers over LPC helpers. Unexpectedly, men preferred HPC messages from male and gender-ambiguous helpers more than they did when HPC messages came from females. Implications follow about computer-mediated emotional support and theories of computer-mediated communication and social influence.
\end{abstract}

doi:10.1111/hcre.12006

Much has been written about the absence of physical cues in text-based computermediated communication (CMC) and the difficulty it imposes in determining what another person's identity truly is. Notorious accounts such as "The Strange Case of the Electronic Lover" (Van Gelder, 1991), as well as more rigorous studies about online self-presentation suggest that the presentation and detection of personal characteristics such as an individual's gender are malleable online (see e.g., Herring \& Martinson, 2004; Roberts \& Parks, 1999; Thomson, Murachver, \& Green, 2001). Aside from isolated and notorious incidences, where might attributions of gender in CMC matter in a theoretically meaningful way? It might in settings where communicators' gender normally triggers a heuristic response to the physical and personality characteristics of the message source that guides receivers' evaluations of the messages that are sent.

Corresponding author: Erin L. Spottswood; e-mail: espottsy@gmail.com 
Computer-mediated emotional support (CMES) may be precisely such a context. According to recent theoretical and empirical studies concerning offline support, the gender of the support seeker and the emotional support provider (hereafter, the "helper") affect the dynamics of face-to-face (FtF) emotional support interactions (Burleson, 2009). Therefore, heuristic cues about the gender of a helper have significant consequences for the interpretations and effectiveness of comforting messages. Computer-mediated support is an analogous technologically-facilitated process, by which thousands of people use the Internet to exchange and obtain emotional support for a variety of illnesses and problems (Braithwaite, Waldron, \& Finn, 1999; Walther \& Boyd, 2002; Wright, 2000; Wright \& Bell, 2003). A recent Pew survey found that nearly $40 \%$ of all American Internet users seek support from online peers (Fox, 2011). With so many people gravitating to CMES, it is no wonder that recent research has sought to examine and understand this phenomenon (e.g., Cunningham \& Barbee, 2000; Gottlieb, 1994; Rains \& Young, 2009; Wright \& Bell, 2003).

Given that the genders of the support seeker and helper make a difference in the effects of offline support messages, how may these gender effects apply in CMES? Computer-mediated social support is normally exchanged among strangers who do not know one another's gender by previous acquaintance. Indeed, one of the foremost attractions to online social support is the anonymity it can provide, due both to the lack of social network overlap and by virtue of the frequent practice of adopting a pseudonym for one's online username (Walther \& Boyd, 2002).

Some researchers have argued that the inability to see communicators' physical appearance occludes the detection of heuristic cues about message senders in CMC (Guadagno \& Cialdini, 2002). If so, it is unclear what gender effects, if any, may accrue when users transmit CMES messages online, especially when cues such as username are gender-ambiguous. Other research suggests that CMC users exploit a variety of language cues to make attributions of others' characteristics that, in turn, aid message processing and evaluation (Van Der Heide, 2008; see for review Walther, 2011). Other CMC research has developed tentative models about motivational states that lead CMC users to identify anonymous senders (Rains \& Scott, 2007). Elsewhere, research found that users of anonymous group decision support systems quite readily make predictions about the identity of other message providers, accurate or not (Hayne \& Rice, 1997). If this is so, readers of CMC should be expected to make gender attributions of message senders based on message characteristics, and these judgments, in turn, should influence message effects.

This research asks, first, whether different types of online support messages lead readers to make attributions about the gender of CMES message senders. Drawing on social information processing (SIP) theory (Walther, 1992), and a review of relevant literature in $\mathrm{CMC}$ and emotional support research, this study proposes that when CMC users have limited information about each other's social and physical attributes, they infer the gender of other users based on senders' message content and the normative association of that content with male versus female helpers. Second, 
drawing on the normative motivation account and dual process theory of supportive messages (Burleson, 2009a) and research on the moderating role of gender in the relationship between message person-centeredness and support effects, this research explores what communicative and evaluative consequences arise in an online support context as a result of gender cues, including ambiguous gender identification of an online helper. Although offline emotional support research suggests that men are less receptive to sensitive emotional support from other men than from women (Burleson, 2009a), Broom (2005) found that men felt more comfortable discussing their feelings and offering emotional support to one another in an online support group. These findings suggest that more research is needed to understand fully the role of gender cues, to which this study contributes. In this way, the present research brings together the person centeredness research that has traditionally been studied regarding face-to-face interaction, where relatively conventional gender issues have been examined, with newer CMC frameworks, where relatively novel and unconventional gender-identification issues are, in fact, quite typical. After discussing relevant literature, this study presents and tests hypotheses using data from a fictitious CMES scenario where participants read and rated different kinds of helpers and their messages.

\section{Using verbal cues to ascertain identity in CMC}

Online support groups, like many virtual communities on the Internet, tend to form when interested individuals discover that others have begun the discussion, rather than through any personal familiarity with other members (see, e.g., Ridings \& Gefen, 2004; Turner, Grube, \& Meyers, 2001; Wellman \& Gulia, 1996). Communication among a large network of strangers provides a greater likelihood of finding relevant expertise than is often found in one's FtF social circle. Such online communication also reduces the risk of embarrassment, thereby facilitating disclosure, because comments are unlikely to leak back into one's normal social network (Walther \& Boyd, 2002). Many individuals also "lurk" in online support groups, that is, they benefit from reading others' messages but they do not contribute messages themselves. One study estimated that lurkers comprised $46 \%$ of the user population of an online health support group (Nonnecke \& Preece, 2000). The process of reading others' messages without participating in the interchange, as the participants in the experiment reported below did, is part of the natural ecology of online support groups. But aside from their common interest in the discussion topic, CMES participants may know very little about one another than what users voluntarily disclose about themselves, and demographic characteristics may be quite absent from such disclosures.

Past research regarding $\mathrm{CMC}$ generally has posited that the relative paucity of nonverbal cues about gender, race, age, and other demographic information should diminish CMC's capacity to foster interpersonal impressions (for review see Walther, 1992). More recent research has found that users are able to exchange social 
information online despite the lack of nonverbal cues: The SIP theory argues that CMC users convert the social information that is typically conveyed nonverbally into verbal, textual, and other linguistic cues that do traverse CMC (Walther, 1992; Walther, Loh, \& Granka, 2005). The medium itself does not alter one's desire to reduce uncertainty and relate to others (Rains \& Scott, 2007), but the medium alters the means by which we form impressions and develop relationships with those we meet online (Hancock \& Dunham, 2001; Walther, 1992; Walther et al., 2005). Other approaches such as the social identification/deindividuation (SIDE) model of CMC have also examined gender attributions online as being a product of categorical social stereotype activation (e.g., Flanagin, Tiyaamornwong, O’Connor, \& Seibold, 2002; Postmes \& Spears, 2002). However, SIDE research tends to examine differences in verbal messages as being the result of gender perceptions rather than as the cues leading to gender perceptions (see for exception Lee, 2007). In contrast, SIP theory focuses explicitly on how CMC users imbue their messages with cues to identity, and how readers decode those cues in building impressions of the message senders.

Typically, among the most obvious cues in FtF communication are the physical characteristics, adornments, kinesics, and vocalics that signal an individual's gender. In CMC, however, the gender of one's CMC partner can be unclear. In accordance with SIP theory's contention that people use verbal information to ascertain characteristics of an online conversational partner, we predict that users will employ verbal information - usernames, message content, and linguistic style - to project gender onto those whose gender is not readily apparent in certain CMC contexts. All three of these verbal cues are discussed in greater detail below.

\section{Usernames}

Usernames are verbal cues that have the potential to implicate the gender of a CMES helper in some cases, but not in all cases. Usernames typically precede the messages members post on an online community's site. Studies show how usernames influence the impression formation process in text-based virtual communities (Cornetto \& Nowak, 2006; Nowak, 2003). Jacobson (1999) interviewed a number of virtual community users and found that self-selected usernames, self-descriptions, and self-disclosures to other users helped interviewees project social and physical characteristics onto those they interacted with online. For example, interviewees' initial descriptions of an individual with the username CrashLander included "strong," "energetic," and "attractive" (Jacobson, 1999, p. 17). Jacobson (1999) argues that "these impressions are based not only on the cues provided but also on the conceptual categories and cognitive models people use in interpreting those cues" (p. 21).

In many cases usernames are gendered, that is, they include names that are normatively associated with males or females. These allow users to make assumptions about the gender of other members of an online community. For example, the username "paul_160" includes a male name, which implies that the person behind the username is male, and other users will likely project a male gender onto "paul_160" due to the male connotation of that username. 
In other cases, usernames accompanying the messages individuals post to such groups may not reveal a user's offline gender. They may be gender-ambiguous because they were intentionally chosen to reflect an aspect of their creator's personality or fantasy (Bechar-Israeli, 1995). They may be unintentionally gender-ambiguous when one's service provider assigns a username comprised of one's last name and first initial. So if a user went by "smithj523" online, the lack of gender information expressed by that username makes it harder for other members to project gender for "smithj523."

\section{Message content}

While a potentially potent type of verbal cue, usernames are not the sole resource users employ to project gender onto those who they encounter in CMC; message content can also inform the projection process. Message content is another kind of verbal cue that can be used to project qualities that are otherwise suggested nonverbally, including a sender's gender, onto those one encounters online (Klemm, Hurst, Dearholt, \& Trone, 1999). In a study examining message content differences between men and women in their e-mails/letters to their friends, Colley et al. (2004) found that the women tended to write more about family, shopping and clubs, a specific incident, and positive emotions than men did. Women also tended to be more affectionate in their signatures and asked more personal questions. These findings are consistent with past research examining differences in what men and women tend to talk about with their friends. If men and women adhere to gender norms as they go online and exchange messages that are exemplary of what is typical of their gender (e.g., writing more about emotions is typical of a woman, less so for a man), other users may project gender on a sender based on their CMC content. For example, users may be more likely to project a female gender onto a user who posts a lot of emotional message content.

Differences in message content have also been shown to help CMC users project personality characteristics onto those they interact with in CMC. Hancock and Dunham (2001) had participants interact in CMC or FtF dyads. Following the encounter, participants rated their interaction partner on neuroticism, extraversion, openness, agreeableness, and conscientiousness. The CMC participants reported more extreme attributions (in terms of neuroticism, extraversion, and agreeableness) about their interaction partners than did the FtF dyads. Even in brief, synchronous $\mathrm{CMC}$, people seem to project characteristics onto those with whom they interact based on message content.

\section{Linguistic style}

Linguistic style is another verbal cue with the potential to help users project physical and social characteristics onto those they meet online, including gender. Men and women have different communication styles offline (Mulac, Bradac, \& Gibbons, 2001; Mulac \& Lundell, 1986) and these differences tend to persist in online group settings (Herring \& Martinson, 2004; Klemm et al., 1999; Newman, Groom, Handelman, 
\& Pennebaker, 2008; Palomares, 2004). For instance, Herring (1993) documented that male and female participants used different linguistic styles in their posts to electronic academic message boards. Males' postings differed from females' on a variety of microlinguistic dimensions. Overall males' posts were more authoritative whereas females' posts were more personal. These differences made it possible "to tell whether a given message was written by a man or a woman, solely on the basis of the rhetorical and linguistic strategies employed" in most cases (Herring, 1993, p. 8). Other studies of mixed-gender online groups appear to reinforce gender differences in language use, whereas single-gender groups or mixed-gender dyads appear to promote less divergent language styles (Savicki, Kelley, \& Oesterreich, 1999; Thomson et al., 2001). In contexts where gender differences pertaining to linguistic style are typical, linguistic style may imply users' gender to those they encounter online.

While all three types of verbal cues influence the projection process in CMC, an absence of one or more of these cues prompts users to rely more heavily on remaining verbal cues to project social and physical characteristics onto other users (Van Der Heide, 2008). Usernames seem like an obvious cue for making gender projections about others one encounters in online emotional support sites, but a potential problem arises if the username includes no information about a helper's gender, because message readers have fewer cues with which to process online support messages. Users may make projections based on message content and linguistic style if a username proves too ambiguous to make a confident gender projection. This study focuses on how CMES message readers make social projections onto emotional support message sources based on the source's username and language behavior. These projections are largely informed by the traditional gender norms associated with how men and women should behave and communicate in FtF emotional support situations. To better understand how these projections operate in CMES, we review the literature on $\mathrm{FtF}$ emotional support norms.

\section{Emotional support}

Emotional support communication is defined as messages that are aimed "to change the feelings of someone who appears to be angry, anxious, despondent, sad, or otherwise upset" (Burleson, 2009a, p. 160). This includes helping recipients to cope and better understand a problem in order to help them feel that they can manage and overcome it. The degree to which an emotional support message is effective or helpful may be based on that message's level of person-centeredness, or "the extent to which messages explicitly acknowledge, elaborate, legitimize, and contextualize the feelings and perspective of a distressed other" (Burleson, 2009, p. 161). Low person-centered (LPC) messages dismiss, criticize, and challenge the legitimacy of the other's feelings and may include statements that tell the recipient how he or she should feel. Highly person-centered (HPC) messages "explicitly recognize and legitimize the other's feelings" and encourage the recipient to articulate, elaborate on, and explore those feelings (Burleson, 2009b, p. 24). 
The results of many studies indicate that observers and recipients perceive HPC messages as the most helpful, sensitive, and effective type of emotional support messages, whereas LPC messages are considered to be the least (for a review, see Burleson, 2003). However, the person-centeredness expressed in a comforting message is not the only influential factor when receivers evaluate helpers and their attempts at support. The helper's gender also influences ratings of emotional support helpers and their comforting messages (Burleson, Holmstrom, \& Gilstrap, 2005).

The person-centeredness conveyed in a support message usually carries a gendered connotation, further influencing recipients' evaluations of support helpers and their messages. LPC messages are typically classified as masculine due to their lesser degree of sensitivity than HPC messages (Burleson et al., 2005). This is consistent with male gender norms regarding what is appropriate and inappropriate for men to say and behave in front of other men. HPC messages are typically classified as feminine due to their use of sensitive and emotional content (Holmstrom, Burleson, \& Jones, 2005). This is consistent with female gender norms that encourage sensitive and nurturing behavior in women. Given the gendered connotation of LPC and HPC messages, LPC messages are typically attributed to a male helper and HPC messages are typically attributed to a female helper (Kunkel \& Burleson, 1999). When members of either gender offer a support message that is inconsistent with what is normative of their gender, evaluations of the helper and their support message tend to suffer (Burleson et al., 2005; Holmstrom et al., 2005).

Several studies have demonstrated that helper gender moderates the effect of message type on evaluations of helpers, especially when those helpers violate gender norms (Burleson, 2009). For example, Burleson et al. (2005) conducted a study in which men and women read transcripts of conversations in which a helper was trying to comfort a distressed same-gender friend. Male participants rated male helpers who used HPC messages to support other males as less likeable and less realistic than male helpers who provided the same HPC messages to females. However, female participants' ratings of HPC helpers did not differ based on the helpers' respective gender.

The dual process theory of social support contends that helpers gender influences support message evaluations more when motivation and/or ability to process the support message is low (Burleson, 2009a). The heuristic of helper gender helps receivers make inferences about the helper and their support messages. By combining the contentions of the dual process theory and the normative motivation account detailed above (Burleson et al. 2005), we theorize that in situations where (a) the listener is unable and/or unmotivated to process the support message and (b) the support message is inconsistent with what is normative of the helper's gender in support situations, the listener will disapprove of the helper and the helper's message given the helper's abnormal behavior and inappropriate support message.

Gender norms that exist offline with respect to emotional support may persist online, thus influencing the projection process in CMES. The studies mentioned above (Burleson, 2009b; Burleson et al., 2005; Kunkel \& Burleson, 1999) were 
designed to get people to imagine that the helper and recipient were interacting FtF, where all the nonverbal cues associated with FtF conversation would be at the disposal of senders, receivers, and observers. In CMES, these same cues are absent from the support interaction, thus limiting the ability of existing theories to predict how people respond to typical and atypical male and female emotional support helpers and messages across different communication media.

CMES has been shown to be a welcome alternative to traditional FtF emotional support (Turner et al., 2001; Walther \& Boyd, 2002), but taking the conversation online does not diminish a support receiver's desire to want to know physical and social characteristics of those who try to offer them support (Ryan, 2006). This may be particularly true for gender judgments, because helper gender shapes the interpretation of the appropriateness (and therefore the effectiveness and likeability) of helpers and the support messages that receivers encounter. Therefore, in CMES, users may project gender onto those they encounter on these sites by interpreting the gendered connotation (or lack thereof) of a username in addition to the content and style of a support message.

The following hypotheses and research question are derived from the principles discussed above regarding SIP theory, traditional FtF emotional support, and CMES:

H1: When a support provider's name is gender ambiguous, men and women attribute support providers' gender (a) as being female when messages are HPC and (b) as being male when messages are LPC.

$\mathrm{H} 2$ : CMC support messages and support sources are evaluated based on the gender of the source and type of support message:

H2a: Males like female and gender-ambiguous helpers who use HPC messages more than male helpers who use HPC messages.

$\mathrm{H} 2 \mathrm{~b}$ : Males rate HPC messages from female and gender-ambiguous helpers as more effective than HPC messages from male helpers.

H2c: Females like helpers who use HPC messages more than helpers who use LPC messages regardless of the gender of the helpers (male, female, or gender-ambiguous).

$\mathrm{H} 2 \mathrm{~d}$ : Females rate HPC messages as more effective than LPC messages regardless of the gender of the helpers (male, female, or gender-ambiguous).

\section{Method}

Two hundred and forty undergraduate students from a large university in the Midwestern United States participated in this study in exchange for research credit in Communication courses. The participants included 170 women $(71.43 \%)$ and 68 men $(28.57 \%)$ who ranged in age from $18-47$ years $(M=25.4, S D=8.76)$.

\section{Pretest}

\section{Usernames}

The usernames and emotional support messages used in this study were pretested to ensure they would elicit their intended effects in the experiment. From a website offering actual, abandoned usernames (http://www.livejour 
nal.com/misc/expunged_list.bml), the researchers selected 20 that intuitively appeared to vary in terms of their gender connotation. Seventeen participants from an undergraduate course whose members were similar to the participants in the main study rated the 20 usernames and indicated whether they believed each username was male, female, or gender-ambiguous. Their responses were coded as +1 for male, -1 for female, and 0 for gender ambiguous. Two usernames emerged as consistently male: obeyfrank $(M=1$, mode $=1)$ and jak2 $(M=0.88$, mode $=1)$. Two were consistently seen as female (Madamdorothy $M=-1$, mode $=-1$; wallflower_dani $M=-1, \operatorname{mode}=-1)$. Two were the most neutral, with modal gender ratings of gender-ambiguous: b0k_choi $(M=0.18$, mode $=0)$, and zy523 $(M=0.24$, mode $=0)$. Although the ratings of the latter two usernames trended most slightly toward classification as male, the hypotheses tests will show this is not problematic. These six were used to operationalize the array of gendered usernames in the main experiment. Another username from this pretest was used for the male support recipient, paul_160 $(M=0.76$, mode $=1)$.

\section{Person-centered messages and situational severity}

This research adapted social support scenarios from previous, offline research on person-centered messages (Burleson et al., 2005; Holmstrom et al., 2005) to the present, computer-mediated context. Pretests were conducted in order to (a) ensure that HPC messages were perceived as more person-centered than LPC messages and (b) verify that the support exchange situation was relatively low in severity. The rationale for a less severe situation is that lower-severity problems are less likely to prompt central processing of support messages, elevating the influence of heuristic (source) qualities in message processing (e.g., see Bodie et al., 2011; Burleson, 2008, Study 3). Because this research was interested in the effects of overt heuristic cues, a situation in which such cues were important provided a more useful test of hypotheses.

The emotional support messages used in this study were created using conventional procedures. First, prospective support statements were adapted so that the total pool included three HPC and three LPC messages that appeared to respond to an online request for support following a more severe problem (breaking up with a long-term romantic partner) and another three HPC and three LPC messages that appeared to respond to a less severe problem (being stood up for a date). Three experts evaluated the prospective support messages. These individuals all completed doctorates with specializations in social support communication, and each has published numerous peer-reviewed journal articles focusing on message person centeredness. Two experts evaluated the six HPC and six LPC messages, and indicated that two HPC messages might reflect only moderately person-centered qualities instead of HPC qualities. These two messages were corrected by a third expert until they both reflected HPC qualities.

To check that HPC messages were perceived as more helpful than LPC messages, an additional sample of 59 participants from the same population as the participants in the main study rated three HPC and three LPC support messages either in the 
Table 1 Means and Standard Deviations for Person Centeredness in HPC and LPC Messages in High- and Low-Severity Conditions

\begin{tabular}{llll}
\hline \multirow{2}{*}{ Situation Severity } & & \multicolumn{2}{c}{ Messages } \\
\cline { 3 - 4 } & & HPC & LPC \\
\hline High & $M$ & $4.16^{\mathrm{a}}$ & $1.49^{\mathrm{b}}$ \\
\multirow{2}{*}{ Low } & $S D$ & 0.41 & 0.52 \\
& $M$ & $3.97^{\mathrm{c}}$ & $1.64^{\mathrm{d}}$ \\
& $S D$ & 0.46 & 0.56 \\
\hline
\end{tabular}

Note: Different superscripts letters indicate statistically significant differences across rows and within columns. $\mathrm{HPC}=$ highly person-centered; $\mathrm{LPC}=$ low person-centered.

context of a high-severity help request or a low-severity problem. In the pretest, the support seeker and helper usernames were kept gender neutral to see how the participants would respond to the varying degrees of person centeredness in the HPC and LPC support messages without biasing responses due to the gender of their sources. Participants evaluated each message using scales adapted from Holmstrom et al. (2005) to assess message helpfulness, including "How effectively do you think User1 responded to (the individual's) problem?" "How much better would (the individual) feel after reading the response message from User 1?" "How much do you think User 1 is concerned about (the individual's) situation?" and "How much do you think User1 cares about (the individual's) situation?" The scales demonstrated acceptable reliability, ranging from $\alpha=0.93$ for LPC messages in the high-severity condition, to 0.73 for the HPC messages in the low-severity condition.

A paired-samples $t$-test compared ratings of HPC and LPC messages in the highand low-severity conditions. There were significant differences between the HPC and LPC messages' perceived helpfulness in the low-severity condition, $t(50)=23.01$, $p<.001, d=0.27$, as well as between the HPC and LPC messages in the highseverity condition, $t(49)=24.22, p<.001, d=0.43$ (note: as a result of some missing responses, the $d f$ in the $t$-tests were reduced to 50 and 49 ). See Table 1 for descriptive statistics. The differential effect sizes for the differences between HPC and LPC messages $(0.27$ for the low-severity and 0.43 for the high-severity situation) reflect that low-severity problem stimuli reduced participants' motivation to distinguish between HPC and LPC messages (Bodie et al., 2011), increasing the likelihood that communicator characteristics would be relatively more salient to observers. Two additional paired samples $t$-tests demonstrated that observers rated similar HPC messages as differentially helpful depending on whether they followed a high- or lowseverity condition, $t(49)=3.79, p<.001, d=0.44$, and that LPC messages differed in perceived helpfulness between the high- and low-severity condition, $t(50)=-2.46$, $p<.05, d=-0.28$. Therefore, the less severe problem and its support responses were used in the main study in order to foster heuristic processing. 


\section{Experiment}

Participants were provided a URL in order to access the SurveyMonkey.com webbased research system that presented all stimuli and that recorded responses. These materials contained (a) a welcome and consent page; (b) six stimulus pages modeled to look like an online support conversation, where a male support seeker posts a problem to an electronic message board and receives either an LPC or HPC message from a male, female, or gender-ambiguous helper; (c) following each ostensible support reply, questionnaire items assessing participants' liking of the helper, perceived effectiveness of the support message, and some filler items. Each research participant viewed and rated all six messages, and then completed (d) additional questions and demographic measures.

Each of the six stimulus pages reflected a message posting indicating the distress situation expressed by the support seeker, paul_160: "Hi, so I have known this girl in my class for a few weeks and she seemed to like me. She flirted with me and sat next to me in class. I thought asking her out would be a good idea. I ask her out, she says yes and we made plans. But she never showed up. It's hard not to take this personally, why do I even bother?" This was followed by a support response post by a male, female, or gender-ambiguous helper. The support seeker was made to appear male in all cases in order to increase the potential variability in evaluations of responses by ostensibly male and gender-ambiguous helpers. Previous research indicates men have different reactions when males versus females provide HPC support to male support seekers (Burleson et al., 2005), but no differences when HPC messages are presented to female support seekers. The present design allowed inspection of whether those differences replicate in CMC. Each of the six stimulus pages contained one support response, with variations that reflected a complete cross of message type (LPC and HPC) and gender of the helper (male, female, and gender-ambiguous). Order of presentation was randomized.

The gender of the helper was indicated by the username that preceded each support message. Male names were jak2 and obeyfrank. Female names were Madamdorothy and wallflower_dani, and gender-ambiguous names were b0k_choi and zy523. Participants read one LPC and one HPC messages from two male, two female, and two gender-ambiguous sources. After reading the support messages, participants rated their liking of each helper and the effectiveness of the support messages. They also answered items regarding their assumptions about the gender of the helper(s). Participants' liking of helpers was assessed with three items adapted from Holmstrom et al. (2005) to fit the present context and sources, e.g., (a) "How much would you like having jak2 as a friend?" (b) "How much would you like to spend time with jak2?" and (c) "How much would you like to talk to jak2?" Reliabilities of these items were good, ranging from $\alpha=0.89$ for zy523 to $\alpha=0.95$ for obeyfrank and wallflower_dani. Perceived effectiveness of support messages was assessed with two items also adapted from Holmstrom et al. (2005), including "How effectively do you think jak2 responded to paul_160's problem?" and "How much better would 
paul_160 feel after reading jak2's post?" Reliability of this measure was lower in some cases: for Madamdorothy, $\alpha=0.75$; but for obeyfrank, $\alpha=0.90$.

Two measures assessed whether participants perceived the gender-ambiguous helpers as male or female. One involved a single-item, binary assessment: "Is b0k_choi (or the other usernames) male or female?" Participants were not given a gender-ambiguous option in order to encourage participants to assign a gender to the helper(s) based on username and message type. The second method employed a 5-interval, single-item semantic differential, anchored masculine to feminine.

\section{Results}

Hypothesis 1 tested participants' responses to the request to indicate the gender of the gender-ambiguous helpers (b0k_choi and zy523). A $\chi^{2}$ analysis was conducted to determine whether participants projected a female gender onto a HPC genderambiguous helper and a male gender onto a LPC gender-ambiguous helper more frequently than would be expected by chance. The result was consistent with the prediction, $\chi^{2}(1,474)=158.74, p<.001, \phi=0.58$. The hypothesis was supported; frequencies appear in Table 2.

Hypothesis 2a predicted that men like female and gender-ambiguous HPC helpers more than they like male HPC helpers. Data analysis employed only male participants' responses. The means clearly did not fall in the predicted patterns; $M$ liking for male HPC helper $=3.93, S D=0.80 ; M$ liking for female HPC helper $=3.65, S D=0.85 ; M$ liking for gender-ambiguous HPC helper $=3.71, S D=0.97, n=68$. The hypothesis was not supported. Follow-up comparisons revealed that the male participants liked male HPC helpers more than they liked either female HPC helpers, $t(67)=2.29$, $p=.025, d=0.55$, or gender-ambiguous HPC helpers, $t(67)=2.15, p=.035$, $d=0.53$, with no differences between female and gender-ambiguous HPC helpers.

Hypothesis $2 \mathrm{~b}$ predicted that men rate female and gender-ambiguous HPC helpers as more effective than male HPC helpers. This hypothesis, too, was not supported, since means did not array in the predicted patterns. Follow-up pairwise tests revealed that the male participants saw female HPC helpers as significantly less effective, $M=3.58, S D=0.88$, than both male HPC helpers, $M=4.01, S D=0.88$, $t(67)=3.16, p=.002, d=0.77$, as well as gender-ambiguous HPC helpers, $M=3.93$, $S D=0.90, t(67)=2.60, p=.012, d=0.64$. Male helpers' and gender-ambiguous helpers' effectiveness did not differ.

Because the dependent variables in $\mathrm{H} 2 \mathrm{c}$ (liking) and $\mathrm{H} 2 \mathrm{~d}$ (effectiveness) were correlated, a Bonferroni correction was employed for these tests, with a critical $p<.025$. Hypothesis $2 c$ predicted that women like HPC helpers more than they like LPC helpers regardless of the gender of the helper. A repeated measures contrast analysis with the six conditions' liking scores as repeated measures using SPSS's GLM procedure indicated that the predicted pattern of the means was obtained, $F(1$, $169)=643.33, p<.001, \eta_{\mathrm{p}}{ }^{2}=0.79$ (see Table 3 for contrast weights and descriptive statistics). The hypothesis was supported. 
Table 2 Gender Projections on Gender-Ambiguous Helpers

\begin{tabular}{lcc}
\hline & \multicolumn{2}{c}{ Source } \\
\cline { 2 - 3 } Gender Attribution & HPC Helper & LPC Helper \\
\hline Male & 56 & 194 \\
Female & 180 & 44 \\
\hline
\end{tabular}

$\chi^{2}(1,474)=158.74, p<.001, \phi=0.58 . \mathrm{HPC}=$ highly person-centered; LPC $=$ low personcentered.

Table 3 Contrast Weights, Means, and Standard Deviations for Women's Liking and Effectiveness Assessments for Helpers as a Function of Helper Gender and Message Person Centeredness

\begin{tabular}{|c|c|c|c|c|c|c|c|}
\hline & & \multicolumn{3}{|c|}{ HPC } & \multicolumn{3}{|c|}{ LPC } \\
\hline & & Male & Female & Ambiguous & Male & Female & Ambiguous \\
\hline Contrast weight & & 1 & 1 & 1 & -1 & -1 & -1 \\
\hline \multirow{2}{*}{ Liking } & $M$ & 4.23 & 3.79 & 3.99 & 2.44 & 1.90 & 1.46 \\
\hline & $S D$ & 0.74 & 0.82 & 0.87 & 1.07 & 0.96 & 0.74 \\
\hline \multirow[t]{2}{*}{ Effectiveness } & $M$ & 4.21 & 3.76 & 4.03 & 2.27 & 1.78 & 1.41 \\
\hline & $S D$ & 0.72 & 0.92 & 0.86 & 1.04 & 0.89 & 0.72 \\
\hline
\end{tabular}

$\mathrm{HPC}=$ highly person-centered; $\mathrm{LPC}=$ low person-centered

Hypothesis $2 \mathrm{~d}$ predicted that women rate HPC helpers as more effective than LPC helpers regardless of the gender of the helper. A repeated measures contrast analysis indicated that the predicted pattern of the means obtained statistical significance, $F(1,169)=796.85, p<.001, \eta_{\mathrm{p}}^{2}=0.83$. This hypothesis, too, was supported (see Table 3 and Figure 1).

\section{Discussion}

This study examined how the presence or absence of gender cues in the usernames of online support providers and the person centeredness of their messages affected projections and evaluations about those helpers in a CMES context. Although many contemporary online support sites provide the opportunity for users to post photos, and the names users choose to represent themselves can be gendered, the case also exists that online support users often appreciate the anonymity that these systems offer (Walther \& Boyd, 2002). When message posters do not identify their gender, readers make gender inferences, and these inferences guide their interpretation of the likeability and effectiveness of the messages. Drawing on the normative motivation account in emotional support research and the dual-process theory of supportive communication outcomes, differences were expected regarding how men 


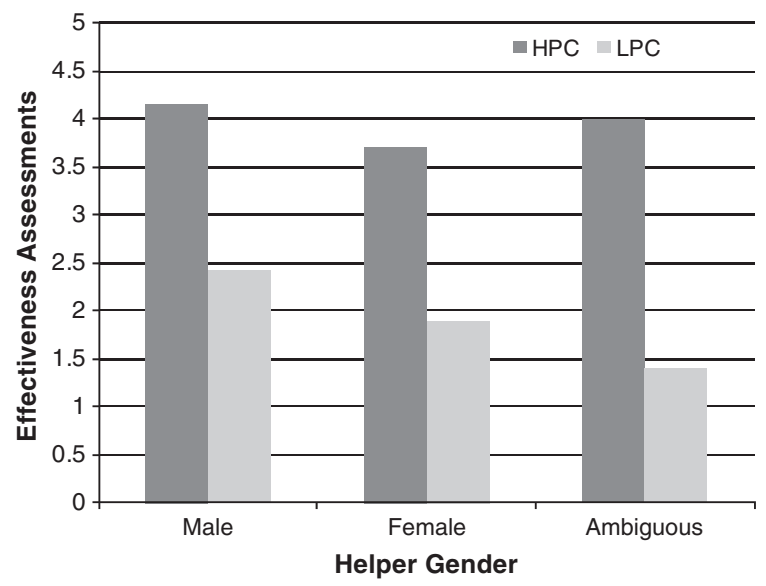

Figure 1 Means for women's assessments of helpers' effectiveness as a function of helpers' gender and message person centeredness.

and women would rate male, female, and gender-ambiguous helpers posting LPC and HPC messages in response to a low-severity distress online post.

This study predicted that the ratings by female observers would replicate those reflected in research on FtF communication, which found that women like HPC helpers more than LPC helpers and rate HPC helpers as more effective than LPC helpers, regardless of the gender of the helper (Burleson et al., 2005). These predictions were supported. This study adds to research on the dual-process theory of supportive communication outcomes and the normative motivation account by examining the claim in a mediated context, and by extending the finding to include gender-ambiguous sources.

However, this study found a different pattern than that which has been reported from offline studies examining the normative motivation account, specifically with respect to males' evaluations of HPC support sources. The normative motivation account of supportive communication would predict that men like female HPC helpers more than male HPC helpers, and the dual-process theory suggests that gender becomes a more salient factor in message judgments when motivation is low. Assuming that readers perceive that HPC message-senders whose usernames are gender-ambiguous are women, they would also like gender-ambiguous HPC helpers. Likewise, men were predicted to rate female and gender-ambiguous HPC helpers as more effective than male HPC helpers.

These predictions were not supported. In fact, male observers evaluated HPC replies written by males more favorably than HPC messages from others. In a computer-mediated context, the observers' ratings in this study suggest that men allow one another greater freedom to provide HPC support messages to other men. This may be because the potential face-threatening implications for a man who responds sensitively toward another man in distress are reduced in a computer-mediated 
context. In a study examining the experiences of men participating in an online support group, Broom (2005) found that, "the men who had used online support groups" appreciate the "potential of online communities to allow them to 'open up' and reduce the inhibitions felt in sharing experiences in FtF situations" (p. 92). In addition, regarding CMC, it "was suggested by several of the respondents that this medium allowed them to bypass 'male tendencies' not to share their feelings and fears in FtF encounters" (Broom, 2005, p. 93).

The alteration of norms may be due, in part, to the mechanics of the communication channel: In CMC, males are unable to deliver tangible aid, that is, the delivery services or resources, which they otherwise typically do in support contexts. Because they are limited to discourse, men may be more sensitive to each other (and perhaps to others) in CMES spaces. Whereas FtF research on social support norms conclude that "guys can't say that to guys" (Holmstrom et al., 2005), this heuristic may be confined to FtF interaction, and it may not be the case that guys cannot write that to other guys.

Moreover, the men in this study may have preferred the HPC male helpers over others because they perceived male helpers to be more likely to understand and support his problem (being stood up for a date by a woman). One of the benefits of online support is being able to access others who know what it feels like to be in a similar situation, and homophily drives credibility in online social support settings (Wang, Walther, Pingree, \& Hawkins, 2008). Perhaps the participants in this study perceived the male helpers as being the best suited to support paul_160 because another man would know what paul_160 is going through more so than a female (or a likely female, in the form of the gender-ambiguous HPC helper). Thus, they may have been influenced by the credibility heuristics of expertise and similarity (see Willemsen, Neijens, \& Bronner, 2012).

Research on CMC demonstrates that people make assumptions and inferences about those they encounter online. Accordingly, we suggested that people use message person-centeredness to project the gender of a gender-ambiguous helper: the female gender for a HPC gender-ambiguous helper and the male gender for an LPC gender-ambiguous helper. This prediction was supported. The majority of the participants in this study projected a female gender onto a HPC gender-ambiguous helper and projected a male gender onto a LPC gender-ambiguous helper with no other individuating information besides the content of the support message. Thus, the person centeredness conveyed in the emotional support messages led the participants to make gender projections onto those with gender-ambiguous usernames. This demonstrates how the content of a message can trigger social projections onto message senders in CMC, whereby the person centeredness conveyed in a support message becomes a cue that implicates the helper's gender.

The manner in which gender attributions corresponded with helper evaluations adds support to Van Der Heide's (2008) integration of the SIP model of CMC with the heuristic-systematic model of persuasion and extends this integrated framework into the domain of research focused on the normative motivations for processing 
social support messages. The framework argues that $\mathrm{CMC}$ users derive impressions of message senders based on the content and style of their verbal remarks. These impressions become heuristic information that guide users' interpretations and decisions in response to the support messages conveying these elements.

Van Der Heide's (2008) work stands in contrast to others' suggestions that CMC bears no heuristic information due to the absence of nonverbal cues to gender and other attributes and that $\mathrm{CMC}$, therefore, leads only to central processing of messages (Guadagno \& Cialdini, 2002). One could point to the current study's results concerning the evaluations by females as support for the latter account: Female observers seemed to pay no attention to gendered or ungendered usernames, and responded only to the central qualities of HPC versus LPC messages. The unexpected results of H2a and H2b, however, are more in line with Van Der Heide's (2008) model: Male observers preferred HPC messages from males more than HPC messages from female or gender-ambiguous sources, indicating that the heuristic judgments of similarity and expertise may have influenced participants' helper evaluations to a greater extent than offline social support norms.

The joint influences of heuristic and central cues come into greater focus when we compare effectiveness ratings across all the cells in the present study. Whereas no hypothesis called for such an analysis, its results provide some illumination of the concurrent influences of source gender by message person-centeredness that reflects all the theoretical notions discussed above. Collapsing across male and female observers, a within-subjects analysis of variance (ANOVA) on perceived message effectiveness revealed a significant interaction of sources' names (male, female, ambiguous) by HPC/LPC message-centeredness, $F(2,474)=50.52, p<.001$, $\eta_{\mathrm{p}}{ }^{2}=0.18$, and a main effect for HPC/LPC messages, $F(1,237)=909.35, p<.001$, $\eta_{\mathrm{p}}{ }^{2}=0.79$; see Table 4 . With regard to the latter (main) effect, all HPC messages were rated more effective than any LPC messages regardless of gender or lack of gender identification. Decomposing the interaction revealed stark differences due to helper gender: Among HPC helpers, males were viewed significantly more effective than gender-ambiguous helpers $(p=.007)$, who were, in turn, more effective than female helpers $(p<.001)$. It appears that the verbal HPC messages themselves provided sufficient social information for observers to infer some attributes of the helper despite the genderlessness of some of the usernames. Although people still assume that it is more likely to be a woman who is providing emotional support to a distressed male, that does not mean women will always be considered the most effective type of supporter. FtF emotional support stereotypes influenced gender projections onto gender ambiguous helpers online, but the nuances of the support scenario in this context seemed to guide participant evaluations more so than the stereotypes alone.

However, in the case of the LPC messages, the gendered usernames provided greater heuristic value, elevating the perceived effectiveness of the messages somewhat, despite the absence of nonverbal cues. Male LPC helpers were seen as more effective than females $(p<.001)$, who in turn were more effective than gender-ambiguous helpers $(p<.001)$. The genderless LPC message, without the heuristic cue of helper 
Table 4 Means and Standard Deviations for Effectiveness Assessments for Helpers as a Function of Helper Gender and Message Person Centeredness

\begin{tabular}{llcccccc}
\hline & \multicolumn{3}{c}{ HPC } & & \multicolumn{3}{c}{ LPC } \\
\cline { 2 - 3 } \cline { 6 - 7 } & Male & Female & Ambiguous & & Male & Female & Ambiguous \\
\hline$M$ & $4.15^{\mathrm{a}}$ & $3.71^{\mathrm{c}}$ & $4.00^{\mathrm{b}}$ & & $2.42^{\mathrm{d}}$ & $1.89^{\mathrm{e}}$ & $1.40^{\mathrm{f}}$ \\
$S D$ & 0.77 & 0.91 & 0.87 & & 1.10 & 0.97 & 0.70 \\
\hline
\end{tabular}

Note: Different superscript letters indicate statistically significant differences. HPC $=$ highly person-centered; $\mathrm{LPC}=$ low person-centered.

gender, may have been interpreted in terms of message quality alone and came up short. Although observers assumed that gender-ambiguous LPC helpers were more likely to be male than female, the gender-ambiguous LPC messages were rated less effective than LPC messages from a male-gendered source. When there is insufficient information about an individual online, SIP asserts, evaluations tend to be impersonal and negative (Walther, 1992). A gendered username (or a HPC or LPC message) provides a cue to identity, and that cue, in turn, improves message evaluations.

\section{Limitations}

This study features several limitations that future research may attempt to address. Although previous empirical studies of online support used naturalistic data - content analysis of postings (e.g., Braithwaite et al., 1999) or unmanipulated surveys (e.g., Walther \& Boyd, 2002) — this study represents the first experiment focusing on online social or emotional support of which we are aware. Because experiments involving CMC require so many potential variables to be rendered fixed for the sake of control, potential confounds may always exist, suggesting caution in accepting results until systematic replications with alternative configurations can be conducted (see Walther, 2011).

This study used the indication of a male support seeker only to examine whether offline findings about men's perceptions of sensitive male helpers would extend to an online environment. However, future research should counterbalance support seekers' gender, as research in offline contexts suggests that helper gender moderates how women rate LPC messages (Holmstrom et al., 2005). We focused on a relatively low-severity support topic in order to maximize the likelihood of triggering the heuristic processes that were of theoretical interest, but future research might examine more involving topics as well.

Previous research about person-centered messages has been conducted mostly using student subjects (e.g., Bodie et al., 2011), to which the present results can readily be compared. Given these precedents, this study developed a support request and responses that seemed quite understandable to a broad array of student participants 
and allowed an initial test of the theoretical juncture of specific CMC issues, online gender cues, and person-centered messages.

Despite the use of a convenience sample of students, certain limitations would arise even from the use of a relatively random sample of Internet users, and these issues raise interesting questions about our findings. Given that a national U.S. survey found that nearly $40 \%$ of Internet users employ online social support (Fox, 2011), we would likely find that a similar proportion of a random sample, or our sample, had experienced online support themselves. One way to study actual users and employ experimental procedures would involve intervening in in situ discussions without prior disclosure or consent, which is questionably ethical and unquestionably resented by virtual community participants themselves (Hudson \& Bruckman, 2004). We must therefore confront the question, what factors may have affected the judgments of the potential $60 \%$ of participants who were relatively less familiar with online social support settings?

Speculatively, their responses might have been shaped by an orientation to more generalized online advice settings. The contemporary "Web 2.0," or participatory web, is replete with systems through which peers advise other peers-from Amazon to Yahoo! Answers-about products, tourist attractions, medical issues, etc., not to mention personal problems (see Walther \& Jang, 2012, for review). In this sense, the results may be reflecting dynamics that are more generalizable than the scope we initially intended. Future research should explore both the issues of intension and extension, where intension is validity with regard to the social support context we specified, and extension refers to broader applicability across other contexts.

In considering more general conclusions, the present results do not lend an answer to the question of primacy in impression formation, although its systematic study would be informative for deciphering what combination of cues-gendered and genderless names, gender-linked content, and gendered language style - affect readers' impressions and interpretations. Which cue is more potent? Is it overridden by the other factors, or is it robust? Psychologists have found that observers quickly form attributions about others' dispositions based on the content of messages they deliver, but observers then modify their attributions when they are led to consider situational constraints that might affect the target (unless observers are cognitively preoccupied; Gilbert, Pelham, \& Krull, 1988). Perhaps first impressions based on one cue are supplanted by another unless (as was not the case in the present study) observers are preoccupied about the topical concern about which they are reading.

In $\mathrm{CMC}$, interface characteristics may also influence primacy. The web design or client program determines what a CMC user sees first - typically a username and subject - suggesting that username may be initially most salient in deciding whether to select, or how to interpret, others' support messages. Indeed, the information in a message header has a significant influence on what messages users select in other CMC contexts (Winter \& Krämer, 2012). These conjectures address what cues may have temporal primacy, but future research is needed to determine the order or weighting among names, content, and style in forming impressions of support providers online. 
This study's findings also support the SIP theory of CMC (Walther, 1992). The majority of the participants in this study projected a female gender onto a HPC gender-ambiguous helper and projected a male gender onto a LPC gender-ambiguous helper. These projections were apparently triggered by the person-centered qualities communicated in the support messages, which are associated with which gender is more likely to use a HPC or LPC message in emotional support scenarios. This finding supports SIP theory's position that receivers use the cues available to them in CMC to form impressions of message senders. Online support users' gender may be unclear due to the lack of nonverbal cues in CMC, but users make inferences and projections about message senders in order to construct impressions of others, which guide their responses to others' messages.

\section{References}

Bechar-Israeli, H. (1995). From < Bonehead $>$ to $<$ cLoNehEAd $>$ : Nicknames, play, and identity on Internet relay chat. Journal of Computer-Mediated Communication, 1(2). Retrieved from http://jcmc.indiana.edu/vol1/issue2/bechar.html

Bodie, G. D., McCullough, J. D., Burleson, B. R., Holmstrom, A. J., Rack, J. J., Gill, J. N., et al. (2011). Explaining the impact of attachment style on evaluations of supportive messages: A dual-process framework. Communication Research, 38, 228-247. doi: 10.1177/ 0093650210362678.

Braithwaite, D. O., Waldron, V. R., \& Finn, J. (1999). Communication of social support in computer-mediated groups for persons with disabilities. Health Communication, 11, 123-151. doi: 10.1207/s15327027hc1102_2.

Broom, A. (2005). The eMale: Prostate cancer, masculinity and online support as a challenge to medical expertise. Journal of Sociology, 41, 87-104. doi: 10.1177/1440783305050965.

Burleson, B. R. (2003). Emotional support skill. In J. O. Greene \& B. R. Burleson (Eds.), Handbook of communication and social interaction skills (pp. 551-594). Mahwah, NJ: Erlbaum.

Burleson, B. R. (2008). What counts as effective emotional support? Explorations of individual and situational differences. In M. T. Motley (Ed.), Studies in applied interpersonal communication (pp. 551-594). Thousand Oaks, CA: Sage.

Burleson, B. R. (2009a). Explaining recipient responses to supportive messages: Development and test of a dual-process theory. In S. W. Smith \& S. R. Wilson (Eds.), New directions in interpersonal communication research (pp. 159-180). Thousand Oaks, CA: Sage.

Burleson, B. R. (2009b). Understanding the outcomes of supportive communication: A dual-process approach. Journal of Social and Personal Relationships, 26, 21-38. doi: 10.1177/0265407509105519.

Burleson, B. R., Holmstrom, A. J., \& Gilstrap, C. M. (2005). “Guys can't say that to guys": Four experiments assessing the normative motivation account for deficiencies in the emotional support provided by men. Communication Monographs, 72, 468-501. doi: $10.1080 / 03637750500322636$.

Colley, A., Todd, Z., Bland, M., Holmes, M., Khanom, N., \& Pike, H. (2004). Style and content in e-mails and letters to male and female friends. Journal of Language and Social Psychology, 23, 369-378. doi: 10.1177/0261927X04266812. 
Cornetto, K. M., \& Nowak, K. L. (2006). Utilizing usernames for sex categorization in computer-mediated communication: Examining perceptions and accuracy. Cyberpsychology \& Behavior, 9, 377-387. doi: 10.1089/cpb.2006.9.377.

Cunningham, M. R., \& Barbee, A. P. (2000). Social support. In C. Hendrick \& S. S. Hendrick (Eds.), Close relationships: A sourcebook (pp. 272-285). Thousand Oaks, CA: Sage.

Flanagin, A. J., Tiyaamornwong, V., O'Connor, J., \& Seibold, D. R. (2002). Computer-mediated group work: The interaction of sex and anonymity. Communication Research, 29, 66-93. doi: 10.1177/0093650202029001004.

Fox, S. (2011). Peer-to-peer healthcare. Pew Internet \& American Life Project. Retrieved March 2011, from http://www.pewinternet.org/Reports/2011/P2PHealthcare.aspx

Gilbert, D. T., Pelham, B. W., \& Krull, D. S. (1988). On cognitive busyness: When person perceivers meet person perceived. Journal of Personality and Social Psychology, 54, 733-740. doi: 10.1037/0022-3514.54.5.733.

Gottlieb, B. H. (1994). Social support. In A. L. Weber \& J. H. Harvey (Eds.), Perspectives on close relationships (pp. 307-324). Boston, MA: Allyn \& Bacon.

Guadagno, R. E., \& Cialdini, R. B. (2002). On-line persuasion: An examination of differences in computer-mediated interpersonal influence. Group Dynamics: Theory, Research and Practice, 6, 38-51. doi: 10.1037/1089-2699.6.1.38.

Hancock, J. T., \& Dunham, P. J. (2001). Impression formation in computer-mediated communication revisited: An analysis of the breadth and intensity of impressions. Communication Research, 28, 325-347. doi: 10.1177/009365001028003004.

Hayne, S. C., \& Rice, R. E. (1997). Attribution accuracy when using anonymity in group support systems. International Journal of Human Computer Studies, 47, 429-452. doi: 10.1006/ijhc.1997.0134.

Herring, S. C. (1993). Gender and democracy in computer-mediated communication. Electronic Journal of Communication, 3(2). Retrieved from http://www.cios.org/www/ ejc/v3n293.htm

Herring, S. C., \& Martinson, A. (2004). Assessing gender authenticity in computer-mediated language use. Journal of Language and Social Psychology, 23, 424-446. doi: 10.1177/ $0261927 X 04269586$.

Holmstrom, A. J., Burleson, B. R., \& Jones, S. M. (2005). Some consequences for helpers who deliver "cold comfort": Why it's worse for women than men to be inept when providing emotional support. Sex Roles, 53, 153-172. doi: 10.1007/s11199-005-5676-4.

Hudson, J. M., \& Bruckman, A. (2004). "Go Away": Participant objections to being studied and the ethics of chatroom research. The Information Society, 20, 127-139. doi: 10.1080/01972240490423030.

Jacobson, D. (1999). Impression formation in cyberspace: Online expectations and offline experiences in text-based virtual communities. Journal of Computer-Mediated Communication, 5(1). doi: 10.1111/j.1083-6101.1999.tb00333.x.

Klemm, P., Hurst, M., Dearholt, S. L., \& Trone, S. R. (1999). Cyber solace: Gender differences on internet cancer support groups. Computers in Nursing, 17(2), 65-72. Retrieved from http://www.cinjournal.com/

Kunkel, A. W., \& Burleson, B. R. (1999). Assessing explanations for sex differences in emotional support: A test of the different cultures and skill specialization accounts. Human Communication Research, 25, 307-340. doi: 10.1111/j.1468-2958.1999.tb00448. 
Lee, E.-J. (2007). Effects of gendered language on gender stereotyping in computer-mediated communication: The moderating role of depersonalization and gender-role orientation. Human Communication Research, 33, 515-535. doi: 10.1111/j.1468-2958.2007.00310.x.

Mulac, A., \& Lundell, T. L. (1986). Linguistic contributors to the gender-linked language effect. Journal of Language and Social Psychology, 5, 81-101. doi: 10.1177/0261927X 8652001.

Mulac, A., Bradac, J. B., \& Gibbons, P. (2001). Empirical support for the gender-as-culture hypothesis: An intercultural analysis of male/female language differences. Human Communication Research, 27, 121-152. doi: 10.1111/j.1468-2958.2001.tb00778.x.

Newman, M. L., Groom, C. J., Handelman, L. D., \& Pennebaker, J. W. (2008). Gender differences in language use: An analysis of 14,000 text samples. Discourse Processes, 45, 211-236. doi: 10.1080/01638530802073712.

Nonnecke, B., \& Preece, J. (2000). Lurker demographics: Counting the silent. Proceedings of CHI 2000. The Hague, the Netherlands: ACM.

Nowak, K. L. (2003). Sex categorization in computer-mediated communication (CMC): Exploring the utopian promise. Media Psychology, 5, 83-103. doi: 10.1207/S1532785X MEP0501_4.

Palomares, N. A. (2004). Gender schematicity, gender identity salience, and gender-linked language use. Human Communication Research, 30, 556-588. doi: 10.1111/j.14682958.2004.tb00745.x.

Postmes, T., \& Spears, R. (2002). Behavior online: Does anonymous computer communication reduce gender inequality? Personality and Social Psychology Bulletin, 28, 1073-1083. doi: 10.1177/01461672022811006.

Rains, S. A., \& Scott, C. R. (2007). To identify or not to identify: A theoretical model of receiver responses to anonymous communication. Communication Theory, 17, 61-79. doi: 10.1111/j.1468-2885.2007.00288.x.

Rains, S. A., \& Young, V. (2009). A meta-analysis of research on formal computer-mediated support groups: Examining group characteristics and health outcomes. Human Communication Research, 35, 309-336. doi: 10.1111/j.1468-2958.2009.01353.x.

Ridings, C. M., \& Gefen, D. (2004). Virtual community attraction: Why people hang out online. Journal of Computer-Mediated Communication, 10(1). doi: 10.1111/j.1083-6101.2004.tb00229.x.

Roberts, L. D., \& Parks, M. R. (1999). The social geography of gender-switching in virtual environments on the Internet. Information, Communication, and Society, 2, 521-540. doi: $10.1080 / 136911899359538$.

Ryan, S. (2006). Trust and participation in online Usenet self-help communities. International Journal of Self Help \& Self Care, 5, 43-72. doi: 10.2190/SH.5.1.f.

Savicki, V., Kelley, M., \& Oesterreich, E. (1999). Judgments of gender in computer-mediated communication. Computers in Human Behavior, 15, 185-194. doi: 10.1016/S7475632(99)00017-5.

Thomson, R., Murachver, T., \& Green, J. (2001). Where is the gender in gendered language? Psychological Science, 12, 171-175. doi: 10.1111/1467-9280.00329.

Turner, J. W., Grube, J. A., \& Meyers, J. (2001). Developing an optimal match within online communities: An exploration of CMC support communities and traditional support. The Journal of Communication, 51, 231-251. doi: 10.1111/j.1460-2466.2001.tb02879.x. 
Van Der Heide, B. (2008, May). Persuasion on the 'net: A synthetic propositional framework. Paper presented at the 58th Annual Conference of the International Communication Association, Montreal, Canada.

Van Gelder, L. V. (1991). The strange case of the electronic lover. In C. Dunlop \& R. Kling (Eds.), Computerization and controversy: Value conflicts and social choices (pp. 364-375). Boston, MA: Academic Press.

Walther, J. B. (1992). Interpersonal effects in computer-mediated interaction: A relational perspective. Communication Research, 19, 52-90. doi: 10.1177/009365092019001003.

Walther, J. B. (2011). Theories of computer-mediated communication and interpersonal relations. In M. L. Knapp \& J. A. Daly (Eds.), The handbook of interpersonal communication (4th ed., pp. 443-479). Thousand Oaks, CA: Sage.

Walther, J. B., \& Boyd, S. (2002). Attraction to computer mediated social support. In C. A. Lin \& D. Atkin (Eds.), Communication technology and society: Audience adoption and uses (pp. 153-188). Cresskill, NJ: Hampton Press.

Walther, J. B., \& Jang, J.-W. (2012). Communication processes in participatory web sites. Journal of Computer-Mediated Communication, 18, 2-15. doi: 10.1111/j.1083-6101. 2012.01592.x.

Walther, J. B., Loh, T., \& Granka, L. (2005). Let me count the ways: The interchange of verbal and nonverbal cues in computer-mediated and face-to-face affinity. Journal of Language and Social Psychology, 24, 36-65. doi: 10.1177/0261927X04273036.

Wang, Z., Walther, J. B., Pingree, S., \& Hawkins, R. (2008). Health information, credibility, homophily, and influence via the Internet: Web sites versus discussion groups. Health Communication, 23, 358-368. doi: 10.1080/10410230802229738.

Wellman, B., \& Gulia, M. (1996). Net surfers don't ride alone: Virtual communities as communities. In M. A. Smith \& P. Kollack (Eds.), Communities in cyberspace (pp. 167-194). Berkeley, CA: University of California Press.

Willemsen, L. M., Neijens, P. C., \& Bronner, F. (2012). The ironic effect of source identification on the perceived credibility of online product reviewers. Journal of Computer-Mediated Communication, 18, 16-31. doi: 10.1111/j.1083-6101.2012.01598.x.

Winter, S., \& Krämer, N. C. (2012). Selecting science information in Web 2.0: How source cues, message sidedness, and need for cognition influence users' exposure to blog posts. Journal of Computer-Mediated Communication, 18, 80-96. doi: 10.1111/j.1083-6101.2012.01596.x.

Wright, K. B. (2000). Perceptions of on-line support providers: An examination of perceived homophily, source credibility, communication and social support within on-line support groups. Communication Quarterly, 48, 44-59. doi: 10.1080/01463370009385579.

Wright, K. B., \& Bell, S. B. (2003). Health-related support groups on the Internet: Linking empirical findings to social support and computer-mediated communication theory. Journal of Health Psychology, 8, 39-54. doi: 10.1177/1359105303008001429. 